Article

\title{
Early-Life Dietary Cadmium Exposure and Kidney Function in 9-Year-Old Children from the PROGRESS Cohort
}

\author{
Edna Rodríguez-López ${ }^{1}$, Marcela Tamayo-Ortiz ${ }^{1,2, *}$, Ana Carolina Ariza ${ }^{1}(\mathbb{D}$, \\ Eduardo Ortiz-Panozo $\left.{ }^{3}{ }^{(}\right)$, Andrea L. Deierlein ${ }^{4}{ }^{(}$, Ivan Pantic ${ }^{5}\left(\mathbb{D}\right.$, Mari Cruz Tolentino ${ }^{6}{ }^{(}$, \\ Guadalupe Estrada-Gutiérrez ${ }^{7} \mathbb{D}^{0}$, Sandra Parra-Hernández ${ }^{7}$, Aurora Espejel-Núñez ${ }^{7}$, \\ Martha María Téllez-Rojo ${ }^{1}$, Robert O. Wright ${ }^{8,9}$ and Alison P. Sanders ${ }^{8,9, *}$
}

1 Center for Nutrition and Health Research, National Institute of Public Health (INSP), Cuernavaca 62100, Morelos, Mexico; edds.rdz@gmail.com (E.R.-L.); carolina.ariza@insp.mx (A.C.A.); mmtellez@insp.mx (M.M.T.-R.)

2 National Council of Science and Technology (CONACyT), Mexico City 03940, Mexico

3 Center for Population Health Research, National Institute of Public Health (INSP), Cuernavaca 62100, Morelos, Mexico; eduardo.ortiz@insp.mx

4 Public Health Nutrition, School of Global Public Health, New York University, New York, NY 10012, USA; ald8@nyu.edu

5 Department of Developmental Neurobiology, National Institute of Perinatology, Mexico City 11000, Mexico; ivandpantic@gmail.com

6 Department of Nutrition and Bio programming, National Institute of Perinatology, Mexico City 11000, Mexico; cruz_tolentino@yahoo.com.mx

7 Department of Immunobiochemistry, National Institute of Perinatology, Mexico City 11000, Mexico; gpestrad@gmail.com (G.E.-G.); rebe1602@hotmail.com (S.P.-H.); aurora_espnu@yahoo.com.mx (A.E.-N.)

8 Department of Environmental Medicine and Public Health, Icahn School of Medicine at Mount Sinai, New York, NY 10029, USA; robert.wright@mssm.edu

9 Department of Pediatrics, Icahn School of Medicine at Mount Sinai, New York, NY 10029, USA

* Correspondence: marcela.tamayo@insp.mx (M.T.-O.); alison.sanders@mssm.edu (A.P.S.)

Received: 21 August 2020; Accepted: 23 September 2020; Published: 7 October 2020

\begin{abstract}
Cadmium (Cd) is a toxic metal associated with adverse health effects, including kidney injury or disease. The aims of this study were to estimate dietary $\mathrm{Cd}$ exposure during childhood, and to evaluate the association of early-life dietary $\mathrm{Cd}$ with biomarkers of glomerular kidney function in 9-year-old Mexican children. Our study included 601 children from the Programming Research in Obesity, Growth, Environment and Social Stressors (PROGRESS) cohort with up to five follow-up food frequency questionnaires from 1 to 9 years of age; and 480 children with measures of serum creatinine, cystatin $C$, and blood nitrogen urea (BUN), as well as 9-year-old estimated glomerular filtration rate. Dietary $\mathrm{Cd}$ was estimated through food composition tables. Multiple linear regression models were used to analyze the association between 1 and 9 years, cumulative dietary $\mathrm{Cd}$, and each kidney parameter. Dietary $\mathrm{Cd}$ exposure increased with age and exceeded the tolerable weekly intake (TWI $=2.5 \mu \mathrm{g} / \mathrm{kg}$ body weight) by $16-64 \%$ at all ages. Early-life dietary Cd exposure was above the TWI and we observed inverse associations between dietary $\mathrm{Cd}$ exposure and kidney function parameters. Additional studies are needed to assess kidney function trajectories through adolescence. Identifying preventable risk factors including environmental exposures in early life can contribute to decreasing the incidence of adult kidney disease.
\end{abstract}

Keywords: cadmium; children; diet; kidney function 


\section{Introduction}

Cadmium $(\mathrm{Cd})$ is a heavy metal found naturally in the environment that has been associated with adverse health effects, such as kidney failure, bone damage, cardiovascular disease, and cancer [1]. Children's exposure to $\mathrm{Cd}$ is of special concern as they may be more susceptible than adults to its toxic effects. Compared to adults, children's food and water intake per body weight is greater, and they have increased intestinal absorption and limited renal excretion [2]. Ingestion and inhalation are the primary routes of exposure to $\mathrm{Cd}$ - primarily through food, tobacco smoke, and dust. Cd accumulation occurs in different tissues and organs [3]. Among the possible target organs of Cd, the kidney is one of the most sensitive organs, wherein $\mathrm{Cd}$ exposure is associated with tubular dysfunction, hypercalciuria, polyuria, tubulointerstitial nephritis, and low-molecular-weight proteinuria, which could lead to kidney failure in later stages [4-6].

There is evidence to suggest that $\mathrm{Cd}$ exposure plays a role in the development of chronic kidney disease $(\mathrm{CKD})$ and that $\mathrm{Cd}$ can be nephrotoxic at environmental levels [5,7]. A recent exposure-wide association study of over 250 chemicals found that $\mathrm{Cd}$ was associated with CKD [8]. Therefore, identifying preventable risk factors, including environmental exposures in childhood, could contribute to our knowledgebase of early-life intervenable factors for decreasing the incidence of CKD [9]. Estimates suggest that 8-16\% of the global population is affected by some form of CKD [7]. Few epidemiological studies have evaluated the association between dietary $\mathrm{Cd}$ and kidney function in children; however, it has been suggested that the mechanism is similar to that of adults for whom there is evidence of dietary Cd exposure and prevalence of CKD [10,11].

Regarding dietary Cd exposure, previous studies have shown elevated tolerable weekly intakes (TWI $=2.5 \mu \mathrm{g} / \mathrm{kg}$ body weight) in children, wherein regularly consumed food items were an important source of Cd [12,13]. A study in Uruguayan children found that Cd levels increased with age [14], and notably, a recent study in Mexican children reported an association between dietary Cd intake and urinary Cd [15]. Despite the existing evidence that children's dietary Cd exposure is elevated, and the importance of early detection of risk factors that may affect children's kidney health, no studies in Mexico have evaluated longitudinal dietary $\mathrm{Cd}$ exposure and its association with kidney function in childhood. Therefore, the aims of this study were: (1) To estimate the dietary exposure of Cd during childhood and identify the primary foods contributing to children's Cd exposure; and (2) to evaluate the association of early-life dietary $\mathrm{Cd}$ exposure with biomarkers of kidney function in 9-year-old Mexican children.

\section{Materials and Methods}

\subsection{Study Population}

This analysis included children from the Programming Research in Obesity, Growth, Environment and Social Stressors (PROGRESS) cohort from Mexico City, which has been previously described in more detail [16]. Briefly, pregnant women receiving care at clinics of the Mexican Institute of Social Security were invited to participate between July 2007 and February 2011. Women were eligible if they were 18 years or older, at $<20$ weeks of gestation, free of heart or kidney disease, did not use steroids or anti-epilepsy drugs, did not consume alcohol on a daily basis, had access to a telephone, and planned to reside in Mexico City for the following three years.

Children were seen at our research facilities at the National Institute of Perinatology, Mexico City (INPer) at 5 follow-up visits when they were 1 year (min 0.98 years, max 1.16 years), 2 years (min 1.95 years, max 2.58 years), 4 years (min 4.00 years, max 6.75 years), 6 years (min 5.96 years, max 9.65 years), and 9 years (min 8.08 years, max 12.06 years). To estimate dietary Cd exposure, we included 601 children who had at least 1 food frequency questionnaire (FFQ) from follow-up visits. For the analysis of kidney function, 480 children with measures of creatinine, cystatin C, blood nitrogen urea (BUN), and estimated glomerular filtration rate (eGFR) at 9 years were included. We excluded children with very low birth weight $(<1500 \mathrm{~g})$ and/or born preterm $(<37$ weeks gestation) $(n=27)$. 
All participants provided written informed consent at the start of the study visit. The study was approved by the internal review boards of the Icahn School of Medicine at Mount Sinai (\#12-00751) and the National Institute of Public Health Mexico (project \#560), 31 October 2017.

\subsection{Diet Data Collection}

Children's diet was assessed using a semiquantitative FFQ that collected food and beverage intake during the previous 7 days [17]. The questionnaire included 101 foods grouped into 14 categories (dairy products, fruits, vegetables, fast food, meat, fish, legumes, cereals, corn products, beverages, snacks, soups, miscellaneous, and tortillas). Frequency values ranged from never consumed, to consumed 7 days per week, as well as times per day that they were consumed with values ranging from consumed 1 to 6 times per day. Serving size (small, medium, large, and very large) and the number of servings consumed were reported. The questionnaire was administered by an interviewer at each of the study visits and answered by the child's mother or caregiver.

\section{Dietary Cadmium}

To estimate dietary $\mathrm{Cd}$, we carried out a search of composition tables reporting Cd levels in food, based on the Total Diet Study (TDS) methodology, which consists of reporting concentrations of contaminants in food [18]. As Mexico lacks such tables, we used tables from the United States, The European Food Safety Authority, Australia, Hong Kong, and Canada. We also used available Cd concentrations measured in selected meat products (ham, sausage, and chorizo) by a study in Mexico City [19]. Each food and beverage item in our FFQ was matched with each of the items found in the Cd composition tables of the different countries. We used the composition tables to obtain an average Cd concentration for each food item, i.e., when the food item was included in all five tables, the average Cd concentration from the tables was used, and so on, if the food item was included in only one table that value was used. In some cases, more than one food item was inquired as the same item on our FFQ (e.g., "broccoli and cauliflower"); for those cases, we used the average Cd for each of the food items from the composition tables. Cd from dishes and prepared foods was estimated (per $100 \mathrm{~g}$ of preparation) using a standardized method that accounts for grams of each ingredient in the recipe. $\mathrm{Cd}$ levels were estimated in $\mu \mathrm{g} /$ day and were reported for each study visit, as well as the "top ten" foods that contribute the most to the $\mathrm{Cd}$ intake according to their frequency of consumption.

We also created a dichotomous variable for children's Cd exposure at each study visit according to the European Food Safety Authority TWI for Cd of $2.5 \mu \mathrm{g} / \mathrm{kg}$ body weight. If the child's Cd intake was above the TWI: High $=1$, or below the TWI: Low $=0$ [20]. Finally, to account for approximate cumulative $\mathrm{Cd}$ exposure, we generated an ordinal $\mathrm{Cd}$ score by adding the Cd TWI high or low from all study visits (scores ranged from $0=$ low exposure in all study visits, to $5=$ high exposure in all study visits). This was done only for children who had dietary information for all five study visits $(n=182)$.

\subsection{Kidney Function Parameters}

Kidney function parameters were determined at 9 years by standardized and trained staff in the Nutrition and Bio-programming Research, and the Immunochemistry department's laboratories at INPer. Fasting blood samples were collected in BD Vacutainer tubes, and serum was separated according to the standard protocol and stored at $-70{ }^{\circ} \mathrm{C}$ until the analysis. The laboratory analyses were carried out using the following methods:

Serum creatinine $(S C r$ ) was measured through the kinetic test without deproteinization according to the Jaffé method [21]. Cystatin C (Cys C) was measured by Quantikine Human Cystatin C enzyme-linked immunosorbent assay. Blood urea nitrogen (BUN) was calculated with the following formula: Serum urea $(\mathrm{mg} / \mathrm{dL}) / 2.14$; serum urea was determined through the Urease-GLDH test: Enzymatic UV test [22]. Estimated glomerular filtration rate (eGFR) was calculated using two formulae: (1) Schwartz formula: eGFR Schwartz $=(k \times$ height $) / S C r$, where $k$ is 0.55 for children under 13 years, 
height is measured in $\mathrm{cm}$, and $\mathrm{SCr}$ is in $\mathrm{mg} / \mathrm{dL}$ [23]; and (2) the 2012 Cystatin C-based equation: $\mathrm{eGFR}_{\text {Cystatin C }}=70.69 \times(\mathrm{CysC})^{-0.931}$, where cystatin C is in $\mathrm{mg} / \mathrm{L}$ [24].

\subsection{Covariates}

Information on secondhand tobacco exposure was obtained by questionnaire; mothers reported the minutes per day that children spent with smokers at 4,6, and 9 years. Children were weighed with the least amount of clothing possible and without footwear using an InBody230, and height was measured with a SECA stadiometer without footwear. The z-score for body mass index (BMI) was estimated according to WHO guidelines [25]: Underweight, normal weight, overweight, and obesity were defined as $<-2 \mathrm{SD},>-2 \mathrm{SD}$ to $\leq+1 \mathrm{SD},>+1 \mathrm{SD}$ to $+2 \mathrm{SD}$, and $>+2 \mathrm{SD}$, respectively. As there were few underweight children, these observations were collapsed to the normal weight category. Physical activity was measured with the International Physical Activity Questionnaire (IPAQ) that was answered by the child's mother at 4, 6, and 9 years. We considered moderate to vigorous activities such as play in the park, run, walk, ride a bike, and dance to estimate minutes of aerobic activities per day. Maternal socioeconomic status was collected at the time of enrollment using a questionnaire according to the Mexican Association of Market Intelligence and Public Opinion Agencies (AMAI, 2007 version). The AMAI classifies Mexican households into seven levels (very low, low, middle-low, middle, middle-high, and high) according to their ability to satisfy the needs of their members. In this study, we collapsed the AMAI levels into three categories: lower, middle, and higher.

\subsection{Statistical Analysis}

We performed descriptive analyses to identify the food items at each study visit that most contributed to the estimated total dietary $\mathrm{Cd}$ intake and reported them as percentages.

We analyzed the distributions and descriptive statistics for each kidney parameter and log-transformed variables for cystatin C, BUN, and eGFR. We used multivariable linear regression models to analyze associations between dietary $\mathrm{Cd}$ at 1 and 9 years with kidney parameters at 9 years. In a subset of children with dietary information across all five study visits, we derived an ordinal cumulative $\mathrm{Cd}$ score. The ordinal score was derived as follows: A score of 0 indicated no exposure throughout the study visits, a score of 1 indicated a high dietary $\mathrm{Cd}$ in one study visit and so forth, and 5 indicated high dietary $\mathrm{Cd}$ in all ages (i.e., 1, 2, 4, 6, and 9 years). We incorporated the ordinal score as a discrete and categorical variable in models and examined associations with each kidney function parameter. Final models were adjusted for sex, age in months (to account for the wider age range at the study visit), BMI z-score, physical activity, secondhand tobacco exposure, and socioeconomic status. All statistical analyses were performed in Stata Statistical Software: Release 14. College Station, TX: StataCorp LP.

\section{Results}

Table 1 shows the participant characteristics at each study visit. Just over half of the children were male, and the age ranged from $12.2 \pm 0.28$ months at the 1-year visit to $116 \pm 8.2$ months at the 9 year visit. Most of the children were of normal weight between 1 and 6 years; however, at 9 years, almost half of the children were overweight $(24.8 \%)$ or obese (22.0\%). Physical activity at 4 and 6 years was $65.8 \pm 30.0$ and $69.73 \pm 29.3 \mathrm{~min} /$ day on average, respectively, and decreased to $21.0 \pm 7.10 \mathrm{~min} /$ day at 9 years. The majority of children (more than $80 \%$ at 4,6 , and 9 years) were not exposed to secondhand tobacco smoke and were of middle or lower socioeconomic status. 
Table 1. Participant characteristics at follow-up study visits.

\begin{tabular}{|c|c|c|c|c|c|}
\hline Study Visit & $\begin{array}{c}\text { 1-Year Visit } \\
n=566\end{array}$ & $\begin{array}{c}\text { 2-Year Visit } \\
n=530\end{array}$ & $\begin{array}{c}\text { 4-Year Visit } \\
n=582\end{array}$ & $\begin{array}{c}\text { 6-Year Visit } \\
n=573\end{array}$ & $\begin{array}{c}\text { 9-Year Visit } \\
n=544\end{array}$ \\
\hline Characteristic & $\begin{array}{c}\text { Mean } \pm \text { SD or } n \\
(\%)\end{array}$ & $\begin{array}{c}\text { Mean } \pm \text { SD or } n \\
(\%)\end{array}$ & $\begin{array}{c}\text { Mean } \pm \text { SD or } n \\
(\%)\end{array}$ & $\begin{array}{c}\text { Mean } \pm \text { SD or } n \\
(\%)\end{array}$ & $\begin{array}{c}\text { Mean } \pm \text { SD or } n \\
(\%)\end{array}$ \\
\hline $\begin{array}{c}\text { Sex } \\
\text { Male }\end{array}$ & $285(50.3 \%)$ & $278(52.4 \%)$ & $293(50.3 \%)$ & $293(51.2 \%)$ & $280(51.4 \%)$ \\
\hline $\begin{array}{l}\text { Age (months) } \\
\text { BMI Z-score }\end{array}$ & $12.2 \pm 0.28$ & $24.4 \pm 0.54$ & $58.5 \pm 6.7$ & $82.1 \pm 7.2$ & $116 \pm 8.2$ \\
\hline Underweight & $15(2.6 \%)$ & $2(0.38 \%)$ & $2(0.34 \%)$ & $7(1.2 \%)$ & $3(0.53 \%)$ \\
\hline Normal weight & $455(80.3 \%)$ & $352(66.4 \%)$ & $474(81.4 \%)$ & $407(71.0 \%)$ & $286(52.5 \%)$ \\
\hline Overweight & $73(12.9 \%)$ & $130(24.5 \%)$ & $68(11.6 \%)$ & $92(16.0 \%)$ & $135(24.8 \%)$ \\
\hline Obesity & $23(4.0 \%)$ & $46(8.6 \%)$ & $38(6.5 \%)$ & $67(11.6 \%)$ & $120(22.0 \%)$ \\
\hline $\begin{array}{l}\text { Physical activity } \\
{\text { (min/day })^{\mathrm{b}}}^{\text {(ming }}\end{array}$ & N/A & N/A & $65.8 \pm 30.0$ & $69.73 \pm 29.3$ & $21.02 \pm 7.10$ \\
\hline $\begin{array}{l}\text { Aerobic activities } \\
\text { Second-hand } \\
\text { smoking (daily) }{ }^{\mathrm{c}}\end{array}$ & N/A & N/A & & & \\
\hline $\begin{array}{l}\text { Yes } \\
\text { No }\end{array}$ & & & $\begin{array}{c}58(10 \%) \\
517(90 \%)\end{array}$ & $\begin{array}{c}75(13 \%) \\
486(86.6 \%)\end{array}$ & $\begin{array}{l}98(18.1 \%) \\
442(81.8 \%)\end{array}$ \\
\hline $\begin{array}{c}\text { Socioeconomic } \\
\text { Status }{ }^{\mathrm{d}} \\
\text { Lower } \\
\text { Middle } \\
\text { Higher }\end{array}$ & $\begin{array}{c}292(51.5 \%) \\
218(38.5 \%) \\
56(9.8 \%)\end{array}$ & & & & \\
\hline
\end{tabular}

Table 2 shows kidney function parameters measured at 9 years; the mean cystatin $C$ was $0.730 \pm 0.17 \mathrm{mg} / \mathrm{dL}$, while the mean BUN was $12.20 \pm 3.09 \mathrm{mg} / \mathrm{dL}$. Using the eGFR ${ }_{\text {CystatinC }}$ formula, there were two children below $60 \mathrm{~mL} / \mathrm{min} / 1.73 \mathrm{~m}^{2}$ and 75 children in the $60-90 \mathrm{~mL} / \mathrm{min} / 1.73 \mathrm{~m}^{2}$ range, while for the eGFR Schwartz, a single child was between 60 and 90 and the rest had and eGFR $\geq 90 \mathrm{~mL} / \mathrm{min} / 1.73 \mathrm{~m}^{2}$. We note that while fewer children had SCr measures, this observation is in line with evidence that SCr-based equations may overestimate eGFR [26].

Table 2. Kidney function parameters from 9-year-old children.

\begin{tabular}{cccc}
\hline $\begin{array}{c}\text { Kidney Function } \\
\text { Parameter }\end{array}$ & $\boldsymbol{n}$ & Mean \pm SD & $\mathbf{( 5 - 9 5 \% )}$ \\
\hline $\begin{array}{c}\text { Serum Creatinine } \\
(\mathrm{mg} / \mathrm{dL})\end{array}$ & 380 & $0.434 \pm 0.09$ & $(0.28-0.59)$ \\
\hline Cystatin C (mg/L) & 455 & $0.730 \pm 0.17$ & $(0.48-1.03)$ \\
\hline BUN $(\mathrm{mg} / \mathrm{dL})$ & 379 & $12.20 \pm 3.09$ & $(7.71-17.9)$ \\
\hline $\begin{array}{c}\mathrm{eGFR} \\
\left(\mathrm{mL} / \mathrm{min} / 1.73 \mathrm{~m}^{2}\right)\end{array}$ & 379 & $180.91 \pm 41.65$ & $(125.43-261.8)$ \\
\hline $\begin{array}{c}\mathrm{eGFR} \\
\left(\mathrm{mL} / \mathrm{min} / 1.73 \mathrm{~m}^{2}\right)\end{array}$ & 455 & $116.55 \pm 28.41$ & $(77.93-166.79)$ \\
\hline
\end{tabular}

Figure 1 shows the primary foods contributing to the estimated dietary intake of Cd from 1 to 9 years of age. At 1 and 2 years, the top contributors were leafy greens ( 1 year: $16.0 \%, 2$ years: 9.0\%), milk (1 year: 10.1\%, 2 years: 9.8\%), and carrots (1 year: 8.8\%, 2 years: $7.9 \%$ ); at 4 years, the top contributors were sweets $(6.8 \%)$, milk $(6.1 \%)$, and carrots $(4.8 \%)$; at 6 years, the top contributors were lettuce $(6.8 \%)$, sandwich $(6.6 \%)$, and sweets $(6.4 \%)$; and at 9 years, the top contributors were lettuce (6.0\%), pasta soup (5.7\%), and sweets (5.5\%). Total dietary Cd intake was $4.43 \pm 2.53 \mu \mathrm{g} / \mathrm{d}$ 
at 1 year; $4.65 \pm 2.45 \mu \mathrm{g} / \mathrm{d}$ at 2 years; $6.00 \pm 3.45 \mu \mathrm{g} / \mathrm{d}$ at 4 years; $6.83 \pm 3.15 \mu \mathrm{g} / \mathrm{d}$ at 6 years; and $8.09 \pm 4.33 \mu \mathrm{g} / \mathrm{d}$ at 9 years. According to the TWI, Cd intakes were exceeded by children at all study visits (study visit, \% children): 1 year, 64\%; 2 years, 49\%; 4 years, 35\%; 6 years, 28\%; and 9 years, $16 \%$. For the cumulative $\mathrm{Cd}$ score $(n=175$ children with information on dietary $\mathrm{Cd}$ in all study visits), we saw that 23 children had low $C d$ across all study visits; 38 children had high $C d$ in one study visit; 57 children had high $\mathrm{Cd}$ in two study visits; 31 children had high $\mathrm{Cd}$ in three study visits; 16 children had high $\mathrm{Cd}$ in four study visits; and 10 children had high $\mathrm{Cd}$ intake in all five study visits.
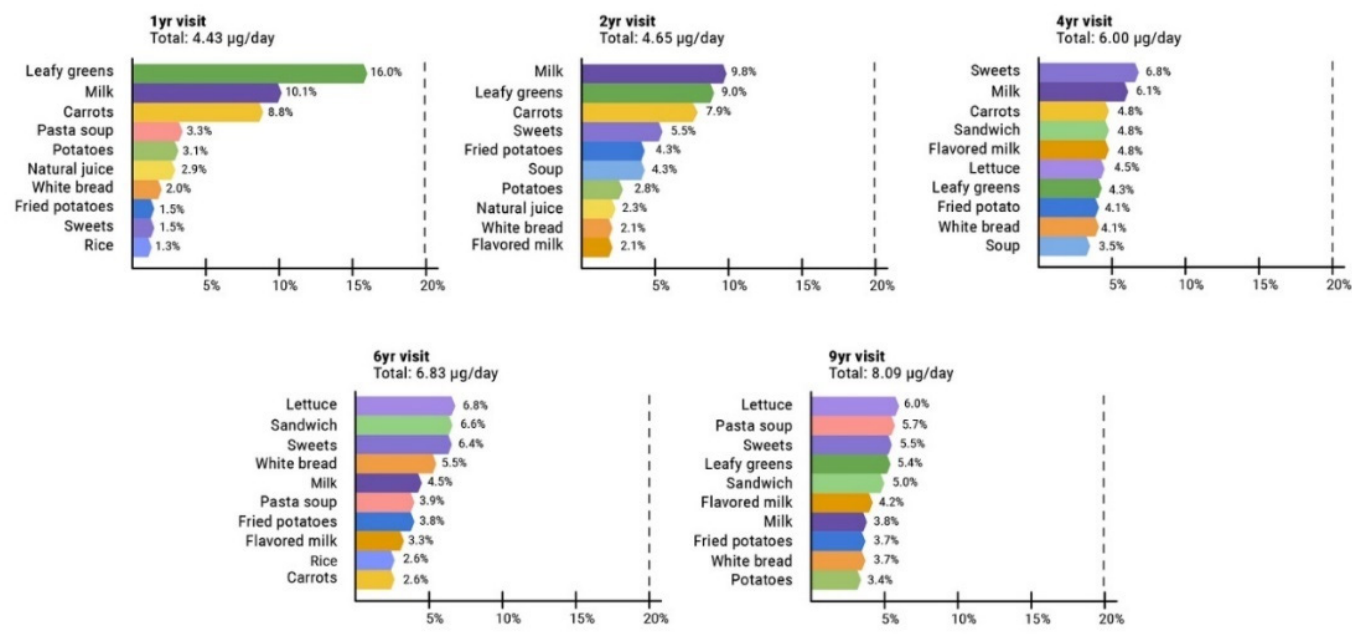

Figure 1. Primary foods contributing to estimated dietary Cd intake in 1-9-year-old children.

For the cross-sectional associations between higher 9-year dietary $\mathrm{Cd}$ and kidney parameters (Table 3), we observed an inverse association between dietary $\mathrm{Cd}$ and BUN ( $\beta=-0.077$ (95\% CI: $[-0.151,-0.003]))$ and, marginally, with $\operatorname{eGFR}_{\text {CystatinC }}(\beta=-0.046(95 \% \mathrm{CI}:[-0.107,0.014]))$.

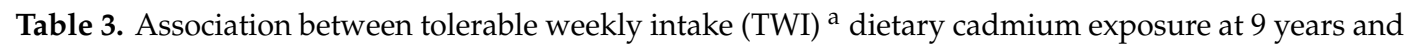
concurrent kidney function parameters in children.

\begin{tabular}{|c|c|c|c|c|c|}
\hline & & & Unadjusted & & Adjusted $^{b}$ \\
\hline & & Low CdD & High CdD & & High CdD \\
\hline & $n$ & & $\beta(95 \% \mathrm{CI})$ & $n$ & $\beta(95 \% \mathrm{CI})$ \\
\hline $\mathrm{SCr}^{\mathrm{c}}(\mathrm{mg} / \mathrm{dL})$ & 375 & Ref & $-0.021(-0.047,0.005)$ & 342 & $-0.013(-0.041,0.015)$ \\
\hline $\begin{array}{l}\text { Cystatin C } \\
(\mathrm{mg} / \mathrm{L})\end{array}$ & 447 & Ref & $0.057(0.001,0.113)$ & 409 & $0.049(-0.010,0.109)$ \\
\hline BUN (mg/dL) & 375 & Ref & $-0.038(-0.111,0.033)$ & 342 & $-0.077(-0.151,-0.003)$ \\
\hline $\begin{array}{l}\text { eGFR } \\
\left(\mathrm{mL} / \mathrm{min} / 1.73 \mathrm{~m}^{2}\right)\end{array}$ & 376 & Ref & $0.020(-0.043,0.084)$ & 343 & $0.022(-0.046,0.091)$ \\
\hline $\begin{array}{l}\text { eGFR }_{\text {Cystatin } C} \\
\left(\mathrm{~mL} / \mathrm{min} / 1.73 \mathrm{~m}^{2}\right)\end{array}$ & 449 & Ref & $-0.053(-0.110,0.004)$ & 411 & $-0.046(-0.107,0.014)$ \\
\hline
\end{tabular}

We observed no significant associations between 1-year dietary $\mathrm{Cd}$ and subsequent children's kidney function (Table 4). 
Table 4. Association between TWI dietary cadmium exposure (high vs. low) ${ }^{a}$ at 1-year and kidney function parameters in 9-year-old children.

\begin{tabular}{|c|c|c|c|c|c|}
\hline & & & Unadjusted & & Adjusted $^{b}$ \\
\hline & & Low CdD & High CdD & & High CdD \\
\hline & $n$ & & $\beta(95 \% \mathrm{CI})$ & $n$ & $\beta(95 \% \mathrm{CI})$ \\
\hline $\mathrm{SCr}^{\mathrm{c}}(\mathrm{mg} / \mathrm{dL})$ & 229 & Ref & $-0.012(-0.039,0.013)$ & 208 & $-0.003(-0.031,0.025)$ \\
\hline Cystatin C (mg/L) & 274 & Ref & $-0.051(-0.110,0.007)$ & 248 & $-0.026(-0.089,0.036)$ \\
\hline BUN (mg/dL) & 229 & Ref & $-0.055(-0.125,0.014)$ & 208 & $-0.011(-0.081,0.059)$ \\
\hline $\begin{array}{l}\text { eGFR }_{\text {Schwartz }} \\
\left(\mathrm{mL} / \mathrm{min} / 1.73 \mathrm{~m}^{2}\right)\end{array}$ & 230 & Ref & $0.027(-0.035,0.090)$ & 209 & $-0.003(-0.072,0.065)$ \\
\hline $\begin{array}{l}\text { eGFR }_{\text {Cystatin C }} \\
\left(\mathrm{mL} / \mathrm{min} / 1.73 \mathrm{~m}^{2}\right)\end{array}$ & 276 & Ref & $0.065(0.004,0.125)$ & 250 & $0.034(-0.029,0.098)$ \\
\hline
\end{tabular}

Finally, we assessed associations with cumulative $\mathrm{Cd}$ intake using an ordinal score, analyzed as discrete and categorical (Table 5). We again identified an inverse association with BUN when using the score as a discrete variable; however, no associations with the other parameters were observed. Using the score as categorical, we observed an inverted "U-shaped" relationship with cystatin C where estimates decreased with an increasing cumulative $\mathrm{Cd}$ score to 3 and then increased with the cumulative $\mathrm{Cd}$ score from 4 and 5; and a negative dose-response for BUN where, as the score increased, the model estimates decreased progressively from -0.006 to -0.187 (Table 5).

Table 5. Association between estimated cumulative dietary $\mathrm{Cd}$ score (as a discrete and categorical variable) and 9-year kidney function parameters ${ }^{\mathrm{a}}$.

\begin{tabular}{|c|c|c|c|c|c|}
\hline $\begin{array}{c}\text { Kidney } \\
\text { Function } \\
\text { Parameter }\end{array}$ & $\begin{array}{c}\mathrm{SCr}^{\mathrm{b}} \\
(n=124)\end{array}$ & $\begin{array}{l}\text { Cystatin C } \\
(n=140)\end{array}$ & $\begin{array}{c}\text { BUN } \\
(n=124)\end{array}$ & $\begin{array}{c}\text { eGFR }_{\text {Schwartz }} \\
\quad(n=124)\end{array}$ & $\begin{array}{c}\text { eGFR }_{\text {CystatinC }} \\
\quad(n=142)\end{array}$ \\
\hline Score & $\beta(95 \% \mathrm{CI})$ & $\beta(95 \% \mathrm{CI})$ & $\beta(95 \% \mathrm{CI})$ & $\beta(95 \% \mathrm{CI})$ & $\beta(95 \% \mathrm{CI})$ \\
\hline Discrete & $-0.011(-0.025,0.002)$ & $-0.019(-0.050,0.010)$ & $\begin{array}{c}-0.037(-0.072 \\
-0.003)\end{array}$ & $0.025(-0.007,0.058)$ & $0.020(-0.011,0.051)$ \\
\hline $0(n=23)$ & Ref & Ref & Ref & Ref & Ref \\
\hline $1(n=38)$ & $0.017(-0.047,0.081)$ & $0.063(-0.083,0.211)$ & $-0.006(-0.168,0.154)$ & $-0.028(-0.182,0.126)$ & $-0.064(-0.216,0.088)$ \\
\hline $2(n=57)$ & $-0.015(-0.075,0.044)$ & $0.053(-0.087,0.193)$ & $-0.041(-0.191,0.107)$ & $0.048(-0.094,0.190)$ & $-0.072(-0.216,0.071)$ \\
\hline $3(n=31)$ & $-0.039(-0.0105,0.026)$ & $-0.082(-0.241,0.075)$ & $-0.092(-0.257,0.073)$ & $0.104(-0.053,0.262)$ & $0.081(-0.082,0.244)$ \\
\hline $4(n=16)$ & $0.000(-0.081,0.081)$ & $-0.028(-0.209,0.151)$ & $-0.129(-0.332,0.073)$ & $0.011(-0.182,0.204)$ & $0.027(-0.159,0.213)$ \\
\hline $5(n=10)$ & $-0.051(-0.147,0.044)$ & $-0.007(-0.202,0.187)$ & $-0.187(-0.428,0.052)$ & $0.100(-0.128,0.328)$ & $0.009(-0.192,0.210)$ \\
\hline
\end{tabular}

\section{Discussion}

In this longitudinal study of 601 Mexican children, we found that the estimated dietary Cd exposure increased with age, from $\sim 4.4 \mu \mathrm{g} / \mathrm{d}$ at 1 year to $8.1 \mu \mathrm{g} / \mathrm{d}$ at 9 years. The main food sources of $\mathrm{Cd}$ changed across all study visits; at 1 and 2 years, leafy greens, milk, and carrots were the primary dietary contributors, and beginning at 4 years, we observed a dietary transition to sweets, lettuce, and sandwiches as the primary contributors. This transition most likely reflects maternal control of the child's dietary intake during the first two years of life and then the child's food preferences influencing intake at older ages. TWI was exceeded at all study visits, with $64 \%$ at 1 year decreasing to $16 \%$ in 9 -year children consuming more $\mathrm{Cd}$ than is recommended. Finally, we found inverse associations between dietary 9-year high Cd intake, as well as the cumulative score and BUN $\beta=-0.077$ (95\% CI: $(-0.151,-0.003))$ and $\beta=-0.037(-0.072,-0.003)$, respectively.

Our results are similar to the $\mathrm{Cd}$ intake observed among 4-12-year-old Australian children where the Cd intake was $4.0 \pm 2.2(0.98-9.5) \mu \mathrm{g} / \mathrm{d}$ [27] but higher than a study from the United States where the mean Cd intake in 2 to 10-year-old children was $2.96(2.83,3.10) \mu \mathrm{g} / \mathrm{d}$ [28]. Regarding the main food contributors, these results are similar to a previous study in the United States where the top Cd 
contributors to children's diet at 10-11 years old were milk, lettuce, and cookies [28]. The TWIs are in line with a study in France that observed that diets of 5-6-year-old children exceeded the Cd TWI by $12-15 \%$ [12], while diets of 1 to 3-year-old and 6-year-old Finnish children exceeded the TWI by $88 \%$ and $64 \%$, respectively [13].

Cd intake was comparable to other populations, suggesting that at these daily intakes, the kidney parameters we studied are not altered in 9-year-old children. There are several possible interpretations of our findings. It is possible that at this early stage of childhood (age 8-12), potential changes in kidney function are not yet apparent. This is likely given that glomerular function, as assessed via eGFR and less specifically with BUN, may not show a marked decrease until substantial dysfunction has occurred [29]. Thus, we note with interest the marginally significant inverse associations with eGFR as early as age 8-12 observed in this study. The earliest indication of kidney damage in humans is typically an increased excretion of low-molecular-weight proteins, such as $\beta 2$-microglobulin, $\alpha 1$-microglobulin, retinol binding protein, and $\mathrm{N}$-acetyl- $\beta$-glucosaminidase, among others; and increased excretion of calcium and metallothionein [30]. We also note that BUN is a nonspecific biomarker that can vary independently of the GFR. BUN can be associated with other factors such as liver dysfunction [31], and low or high BUN may be related to undesirable states like malnutrition, starvation, dehydration, high protein intake, among others [32]. Future studies should assess biomarkers of subclinical injury, including urinary proteins like $\beta 2$-microglobulin and additional assessment of liver function.

Another interpretation is that there is no kidney damage at these $\mathrm{Cd}$ intake concentrations. We would not anticipate 'normal' dietary levels of $\mathrm{Cd}$ to cause clinically apparent kidney dysfunction. However, there is evidence that when $\mathrm{Cd}$ reaches between 50 and $300 \mu \mathrm{g} / \mathrm{g}$ wet weight in the kidney cortex, the amount of $\mathrm{Cd}$ not bound to metallothionein becomes sufficiently high to cause tubular damage [30]. Studies have estimated that to reach these Cd levels, a Cd intake of $>200 \mu \mathrm{g} / \mathrm{day}$ or lifetime intake of $1300 \mathrm{mg}$ is necessary [33]. Lastly, it is possible that a compensatory mechanism exists, where kidney function in healthy children can cope with this level of $\mathrm{Cd}$ insult, while high levels of $\mathrm{Cd}$ are nephrotoxic [34].

An important limitation of our study is the estimation of dietary Cd using FFQs, as these can introduce measurement error from maternal recall. It is unlikely though that this could have led to bias as mothers were unaware of the research question (i.e., did not answer the questionnaire in terms of $\mathrm{Cd}$ exposure or kidney function). Nonetheless, FFQs are also subject to measurement error as, beyond maternal recall, children spend time in school or in other contexts where they consume food items most likely not reported in the FFQ. Furthermore, we did not measure the concentrations directly in food items. Except for $\mathrm{Cd}$ concentrations for a few food items (processed meat) reported in a study of adults in Mexico City [19], we used data from nutrient composition tables from different countries, where the $\mathrm{Cd}$ concentrations reported for food items may be different from Mexico. Ideally, our study would have measured the Cd concentrations in food items reported in the FFQ and purchased samples in local markets; however, this was beyond the scope of this study. By using food content tables from the United States, The European Food Safety Authority, Australia, Hong Kong, and Canada, we aimed at having a higher diversity of food items, as well as a higher variability for the Cd concentrations, also considering the reality of globalized food supply chains and the availability of international food products in Mexican markets.

We therefore cannot rule out that we either under- or over-estimated Cd intake; however, the results are in line with levels reported in previous studies. For example, a study conducted by the United States Food and Drug Administration showed that the top contributors to dietary Cd were grains, prepared foods (e.g., hamburgers, pizza, lasagna, soups), and vegetables [2]; a study of French children showed that the main contributors to dietary Cd were bread and potatoes [35]; and a study of Chinese children found that the three greatest contributors to dietary $\mathrm{Cd}$ were rice, leafy vegetables, and wheat flour [36]. Further, Cd intake estimated by FFQ does not reflect its absorption, metabolism, or excretion. $\mathrm{Cd}$ absorption differs between individuals based on their nutritional status, particularly levels of zinc and iron. For this study, we lacked data on indicators of children's nutritional status of these 
micronutrients. We also lacked urinary Cd measurement, which is an indicator of body burden [37]. PROGRESS has archived urine samples in which $\mathrm{Cd}$ concentrations will be analyzed in future studies.

Among the strengths of this study are the repeated measurements of diet at five stages ranging from 1 to 9 years of age. An important observation of this study was the marked increase in children with overweight or obesity; at 4 years, only $18 \%$ of the children presented with overweight or obesity, but by age 9 years, this increased to $46.8 \%$. We also observed an important decrease in physical activity between 6 and 9 years. Both obesity and physical activity are important metabolic risk factors that could modify the association between $\mathrm{Cd}$ exposure and kidney parameters $[33,38]$. Future studies will directly assess the role of obesity and physical activity as risk factors for longitudinal childhood kidney function trajectories.

Although we did not observe significant associations between children's Cd intake and kidney parameters, the TWI for Cd was exceeded at all study visits, from 1 to 9 years of age. The TWI for Cd is based on preventing downstream effects on kidney, bone, and cardiovascular health in adulthood because it can accumulate throughout life. Follow-ups of this study population at later life stages will elucidate possible Cd nephrotoxicity.

Author Contributions: Conceptualization, E.R.-L., M.T.-O., A.C.A. and A.P.S.; data curation, A.P.S.; formal analysis, E.R.-L., M.T.-O., A.C.A., E.O.-P., G.E.-G. and A.P.S.; funding acquisition, M.M.T.-R., R.O.W. and A.P.S.; investigation, E.R.-L. and M.T.-O.; methodology, E.R.-L., M.T.-O., A.C.A., E.O.-P., M.C.T., G.E.-G., S.P.-H., A.E.-N. and A.P.S.; project administration, M.T.-O., I.P., M.M.T.-R., R.O.W. and A.P.S.; resources, I.P. and R.O.W.; supervision, M.T.-O., A.C.A., E.O.-P., M.M.T.-R. and A.P.S.; writing-original draft, E.R.-L., M.T.-O., A.C.A., E.O.-P. and A.P.S.; writing-review and editing, E.R.-L., M.T.-O., A.C.A., E.O.-P., A.L.D., I.P., M.C.T., G.E.-G., S.P.-H., A.E.-N., M.M.T.-R., R.O.W. and A.P.S. All authors have read and agreed to the published version of the manuscript.

Funding: This work was supported in part by funding from the NIH/NIEHS: K99ES027508, R00ES027508, R01ES013744, R01ES020268, and R01ES021357.

Acknowledgments: Authors thank the National Institute of Perinatology, Mexico for the support provided by its facilities.

Conflicts of Interest: The authors declare no conflict of interest.

\section{References}

1. Wang, Z.; Pan, L.; Liu, G.; Zhang, H.; Zhang, J.; Jiang, J. Dietary exposure to cadmium of Shenzhen adult residents from a total diet study. Food Addit. Contam. Part A 2018, 35, 706-714. [CrossRef]

2. Spungen, J.H. Children's exposures to lead and cadmium: FDA total diet study 2014-2016. Food Addit. Contam. Part A Chem. Anal. Control. Expo. Risk Assess 2019, 36, 893-903. [CrossRef] [PubMed]

3. Nikic, D.; Stankovic, A. Estimated daily intake of cadmium by children living in the city of Nis, Serbia. Turk J. Pediatr 2009, 51, 257-263. [PubMed]

4. Goyer, R.A. Mechanisms of lead and cadmium nephrotoxicity. Toxicol. Lett. 1989, 46, 153-162. [CrossRef]

5. Prozialeck, W.C.; Edwards, J.R. Mechanisms of cadmium-induced proximal tubule injury: New insights with implications for biomonitoring and therapeutic interventions. J. Pharmacol. Exp. Ther. 2012, 343, 2-12. [CrossRef]

6. de Burbure, C.; Buchet, J.P.; Leroyer, A.; Nisse, C.; Haguenoer, J.M.; Mutti, A.; Smerhovský, Z.; Cikrt, M.; Trzcinka-Ochocka, M.; Razniewska, G.; et al. Renal and neurologic effects of cadmium, lead, mercury, and arsenic in children: Evidence of early effects and multiple interactions at environmental exposure levels. Environ. Health Perspect. 2006, 114, 584-590. [CrossRef]

7. Orr, S.E.; Bridges, C.C. Chronic Kidney Disease and Exposure to Nephrotoxic Metals. Int. J. Mol. Sci. 2017, $18,1039$.

8. Lee, J.; Oh, S.; Kang, H.; Kim, S.; Lee, G.; Li, L.; Kim, C.T.; An, J.N.; Oh, Y.K.; Lim, C.S.; et al. Environment-wide association study of CKD. Clin. J. Am. Soc. Nephrol. 2020, 15, 766-775. [CrossRef]

9. Zheng, L.Y.; Sanders, A.P.; Saland, J.M.; Wright, R.O.; Arora, M. Environmental exposures and pediatric kidney function and disease: A systematic review. Environ. Res. 2017, 158, 625-648. [CrossRef]

10. Shi, Z.; Taylor, A.W.; Riley, M.; Byles, J.; Liu, J.; Noakes, M. Association between dietary patterns, cadmium intake and chronic kidney disease among adults. Clin. Nutr. 2017, 37, 276-284. [CrossRef] 
11. Ferraro, P.M.; Costanzi, S.; Naticchia, A.; Sturniolo, A.; Gambaro, G. Low level exposure to cadmium increases the risk of chronic kidney disease: Analysis of the NHANES. BMC Public Health 2010, 10, 304. [CrossRef] [PubMed]

12. Jean, J.; Sirot, V.; Hulin, M.; Le Calvez, E.; Zinck, J.; Noël, L.; Vasseur, P.; Nesslany, F.; Gorecki, S.; Guérin, T.; et al. Dietary exposure to cadmium and health risk assessment in children-Results of the French infant total diet study. Food Chem. Toxicol. 2018, 115, 358-364. [CrossRef] [PubMed]

13. Mykkänen, H.; Räsänen, L.; Ahola, M.; Kimppa, S. Dietary intakes of mercury, lead, cadmium and arsenic by Finnish children. Hum. Nutr. Appl. Nutr. 1986, 40, 32-39.

14. Burganowski, R.; Vahter, M.; Queirolo, E.I.; Peregalli, F.; Baccino, V.; Barcia, E.; Mangieri, S.; Ocampo, V.; Mañay, N.; Martínez, G.; et al. A cross-sectional study of urinary cadmium concentrations in relation to dietary intakes in Uruguayan school children. Sci. Total Environ. 2019, 658, 1239-1248. [CrossRef] [PubMed]

15. Moynihan, M.; Peterson, K.E.; Cantoral, A.; Song, P.X.K.; Jones, A.; Solano-González, M.; Meeker, J.D.; Basu, N.; Téllez-Rojo, M.M. Dietary predictors of urinary cadmium among pregnant women and children. Sci. Total Environ. 2017, 575, 1255-1262. [CrossRef] [PubMed]

16. Braun, J.M.; Wright, R.J.; Just, A.C.; Power, M.C.; Tamayo-Ortiz, M.; Schnaas, L.; Hu, H.; Wright, R.O.; Tellez-Rojo, M.M. Relationships between lead biomarkers and diurnal salivary cortisol indices in pregnant women from Mexico City: A cross-sectional study. Environ. Health 2014, 13, 50. [CrossRef] [PubMed]

17. Rodríguez-Ramírez, S.; Mundo-Rosas, V. Methodology for the analysis of dietary data from the Mexican National Health and Nutrition Survey 2006. Salud Publica Mex. 2009, 51, 523-529. [CrossRef]

18. Kim, C.I.; Lee, J.; Kwon, S.; Yoon, H.J. Total diet study: For a closer-to-real estimate of dietary exposure to chemical substances. Toxicol. Res. 2015, 31, 227-240. [CrossRef]

19. Torres-Sánchez, L.; Vázquez-Salas, R.A.; Vite, A.; Galván-Portillo, M.; Cebrián, M.E.; Macias-Jiménez, A.P.; Ríos, C.; Montes, S. Blood cadmium determinants among males over forty living in Mexico City. Sci. Total Environ. 2018, 637-638, 686-694. [CrossRef]

20. Panel, E.; Chain, F. Statement on tolerable weekly intake for cadmium. EFSA J. 2011, 9, 1975.

21. Jaffe, M. Ueber den Niederschlag, welchen Pikrinsäure in normalem Harn erzeugt und über eine neue Reaction des Kreatinins. Z. Für Physiol. Chem. 1886, 10, 391-400.

22. Sarkar, R. Establishment of Biological Reference Intervals and Reference Curve for Urea by Exploratory Parametric and Non-Parametric Quantile Regression Models. EJIFCC 2013, 24, 61-67. [PubMed]

23. Schwartz, G.J.; Muñoz, A.; Schneider, M.F.; Mak, R.H.; Kaskel, F.; Warady, B.A.; Furth, S.L. New equations to estimate GFR in children with CKD. J. Am. Soc. Nephrol. 2009, 20, 629-637. [CrossRef] [PubMed]

24. Schwartz, G.J.; Schneider, M.F.; Maier, P.S.; Moxey-Mims, M.; Dharnidharka, V.R.; Warady, B.A.; Furth, S.L.; Mũoz, A. Improved equations estimating GFR in children with chronic kidney disease using an immunonephelometric determination of cystatin C. Kidney Int. 2012, 82, 445-453. [CrossRef]

25. WHO Multicentre Growth Reference Study Group. WHO Child Growth Standards: Methods and Development; WHO: Geneva, Switzerland, 2014; p. 312.

26. Pottel, H.; Hoste, L.; Dubourg, L.; Ebert, N.; Schaeffner, E.; Eriksen, B.O.; Melsom, T.; Lamb, E.J.; Rule, A.D.; Turner, S.T.; et al. An estimated glomerular filtration rate equation for the full age spectrum. Nephrol. Dial. Transpl. 2016, 31, 798-806. [CrossRef] [PubMed]

27. Tinggi, U.; Schoendorfer, N. Analysis of lead and cadmium in cereal products and duplicate diets of a small group of selected Brisbane children for estimation of daily metal exposure. J. Trace Elem. Med. Biol. 2018, 50, 671-675. [CrossRef]

28. Kim, K.; Melough, M.M.; Vance, T.M.; Noh, H.; Koo, S.I.; Chun, O.K. Dietary cadmium intake and sources in the US. Nutrients 2019, 11, 2. [CrossRef]

29. Greenberg, J.H.; Kakajiwala, A.; Parikh, C.R.; Furth, S. Emerging biomarkers of chronic kidney disease in children. Pediatr. Nephrol. 2018, 33, 925-933. [CrossRef]

30. ATSDR. Toxicological Profile for Cadmium; US Department of Health and Humans Services, Public Health Service: Atlanta, GA, USA, 2012.

31. Lopez-Giacoman, S. Biomarkers in chronic kidney disease, from kidney function to kidney damage. World J. Nephrol. 2015, 4, 57. [CrossRef]

32. Hosten, A.O. BUN and Creatinine. Clinical Methods: The History, Physical, and Laboratory Examinations, 3rd ed.; Butterworths: Boston, MA, USA, 1990; ISBN 040990077X.

33. Satarug, S. Dietary cadmium intake and its effects on kidneys. Toxics 2018, 6, 15. [CrossRef] 
34. Saif, M.; Rahman, U.R.; Ali, M.U.; Shoaib, M.; Amin, M.A. Cadmium Induced Nephrotoxicity: Advances and Perspectives. Trends Biosci. 2015, 8, 5167-5175.

35. Marín, S.; Pardo, O.; Báguena, R.; Font, G.; Yusà, V. Dietary exposure to trace elements and health risk assessment in the region of Valencia, Spain: A total diet study. Food Addit. Contam. 2017, 34, 228-240. [CrossRef] [PubMed]

36. Song, Y.; Wang, Y.; Mao, W.; Sui, H.; Yong, L.; Yang, D.; Jiang, D.; Zhang, L.; Gong, Y. Dietary cadmium exposure assessment among the Chinese population. PLoS ONE 2017, 12, e0177978. [CrossRef] [PubMed]

37. International Program on Chemical Safety; Friberg, L.; Elinder, C.-G.; Kjellström, T.; United Nations Environment Programme; International Labour Organisation; World Health Organization; International Program on Chemical Safety. Cadmium-Environmental Health Criteria 134; World Health Organization: Geneva, Switzerland, 1992; ISBN 9241571349.

38. Sowers, J.R. Metabolic risk factors and renal disease. Kidney Int. 2007, 71, 719-720. [CrossRef]

(C) 2020 by the authors. Licensee MDPI, Basel, Switzerland. This article is an open access article distributed under the terms and conditions of the Creative Commons Attribution (CC BY) license (http://creativecommons.org/licenses/by/4.0/). 